when regulated by watching the opsonic index. The value of direct immunization in certain other diseases has already been abundantly proved, and the value of the determination of the opsonic index as a guide to dosage and as a measure of progress in treatment has been clearly demonstrated. It seems possible that we are almost within measurable distance of a satisfactory specific treatment for tuberculosis, and the work of Wright has undoubtedly brought us a good step nearer the goal Whether the specific treatment, when found, will be generally applicable to the cure of pulmonary tuberculosis, as well as to tuberculosis of other organs, is a matter of conjecture.

Whilst we are on the look-out for curative serums it might be worth while to see if we cannot obtain from the chief manufactories of antibodies-namely, the lymphatic glands of an infected animal-some extract containing the protective substances. Dr. Paterson of Glasgow has made some clinical observations in this direction in the case of tuberculosis. ${ }^{8}$

Though I am not sanguine as to the probability of curing pulmonary tuberculosis by either direct or indirect immunization, I think it quite possible that prophylactic immunization might be accomplished. Seeing the tremendous incidence and mortality of tuberculous diseases it would seem that "vaccination" against tuberculosis would be quite as justifiable and quite as uselul as vaccination against small-pox.

REFERENCES

1 Starling. Croonian Lectures, Lancet. August 5th to 26th, 1905 Beebe and Buxton, Elements of Physiological Chemistry. 3 Wright and Douglas, Proc. Royal Sociely of Pl. 20nd 1906. 6 Crace-Calvert Lancet, Fobruary 2nd, 1907, 7 wright, Trans. Roy. Med. Chir. Soc., 1906, p. 7. 8 Paterson, Lancet, August 25 th, 1906, p. 493.

\section{A CONTRIBUTION TO}

THE VALUE OF COMPLETE VOCAL REST AS

AN AID TO RECOVERY FROM LARYNGEAL TUBERCULOSIS AND ALLIED CONDITIONS DURING SANATORIUM TREATMENT.

By H. G. FELKIN, M.D.Lond., PHYSICIAN AT THE LINFORD SANATORIUM, NEW FOREST.

From the experience gained by Dr. R. Mander Smyth and myself, at Linford, I should like to add my testimony to the value of complete rest as a powerful aid to recovery from laryngeal tuberculosis during sanatorium treatment.

It has struck me as suggestive that people who have used their voice a great deal, as in singing for instance, are, when they do get pulmonary tuberculosis, more prone to develop laryngeal tuberculosis than others. Vocal rest is but a common-sense application of Hilton's principle, -rest for a diseased or injured part. A tuberculous joint is given absolute rest for many months by fixing not only itself but also the joints above and below it, and, aided by general hygienic measures, recovery takes place in many cases. The principle is true for the tuberculous largnx also, but unfortunately we cannot give it the same measure of rest as a joint. Still, much may be done, and I find the simile just used useful in explaining the great importance of complete vocal rest to patients. The rest must be complete, even whispering should not be indu]ged in. All unnecessary coughing must be suppressed. The laryngeal movements associated with "clearing the throat," a constant habit with some patients, must as far as possible be done away with. The nearer the disease approaches the cords; arytenoids, or argtenoid fold, the greater is the importance of laryngeal rest. It has been said that no fool will ever get cured of pulmonary tuberculosis. This statement is even truer of laryngeal tubercle. I have never yet known a patient refase to carry out this treatment when once the simple principle underlying it had been grasped. A hint to other patients will make them helpfal, and not an additional difficulty to the sufferer. Nasal breathing should be encouraged as a habit, because it is a further safeguard against useless coughing. In febrile cases the isolation in bed in their own room almost ensures silence. When the patient finds, as.is generally the case, that improvement is taking place, this acts in itself as a powerful incentive to perseverance. Most of our patients have nsed either a small notebook and pencil or a small slate for communicating with others; some $f \in w$ have learnt to talk on their fingers with their special friends. I have seen many cases of slight and moderate laryngeal catarrh associated with pulmonary tuberculosis clear up aiter a short period of a few weeks' more or less complete vocal rest; but these cases are common and not worth recording. One case of failt $r$ may here be mentioned, that of a lady who developed a eevere tuberculous luryngitis under observation, involving great swelling and nlceration of both ventricular bands, and in which complete silence could not be enforced, though the necessity was strongly impressed upon her from the very commencement of the disease, and in whi $\mathrm{h}$ a continuous harrassing, and uncontrollable cough frustrated all efforts of obtaining even approximately laryngeal rest. She did badly, but the ulceration improved under vigorous lactic acid treatment.

Of the following illustrations, Group I comprises the histories up to date of 4 cases recorded in Sir Felix Semon's paper in the BRitish MEDICAL Journal of December 8 th, 1906, and which have been under the care of Dr. R. Mander Smyth and myself.

Group II consists of 3 cases of undoubted laryngeal tubercle and of 4 of severe and obstinate catarrh associated with pulmonary tuberculosis.

Case I (Mrs. N.) is, with the exception of Mrs. C. (Group I), the severest case of laryngeal disease associated with advanced chest disease in which $I$ have seen great improvement without any local treatment. In Case II (Mrs. M.) a considerable ulcer healed rapidly and completely in a way it would not, I think, have done with lactic acid only.

Grove I.

Mrs. C. returned to Linford on Fiovember 6th, 1906, her larynx being in the condition described in Sir Felix Semon's paper. In spite of the attack of pleurisy and haemoptysis there was no material alteration in the state of the lungs. Her temperature was normal. She was treated with tuberculin. Strict silence was again maintained, and the only local laryngeal treatment consisted of an insufflation of a mentho and boracic powder three times a day. She complained a good deal of an uncomfortable "swollen" feeling in the larynx. deal of an uncomfortable "swollen" feeling in the larynx. On January 9th, 1907, there was distinctly less swelling over
the arytenoids, but their inner aspect was still reddened. The the arytenoids, but their inner aspect was still reddened. The February 27 th the left arytenoid was very little swollen or reddened. The swelling on the arytenoid fold was smaller, and the right ary tenoid was still swollen though less reddened. She left on March 18th, 1907, having gained $5 \mathrm{lb}$. in weight. The uncomfortable sensation in the larynx was very slight and only occasional, and the swellings of the arytenolds and over the ary tenoid fold had a!most completely subsided. The sputum the arytenoid fold had a!most completely subsided.

Miss S. returned to Linford for the winter on October 5tb, 1906, in good general health and state of nutrition. The laryngeal scars were quite sound and the voice normal. About once in ten days she brought up a small piece of sputum the size of a small pea, which still contained tubercle bacilli. There were a few post-tussic crepilations over the left upper lobe. The temperature was normal and remained so. She used her voice very freely. She left on May 4th, 1907, in good general health. The sputum and physical signs in the lungs continued as above described. The scars is the larynx became continued as above described. The Ecars if the larynx became quite inconspicuous. This was contirmed shortly after her
departure by Sir Felix Semon, . who even allowed her to cautious] begin singing again.

$\mathbb{N}$ is W. returned to Linford on October 29th, 1906. The larynx was in the condition last described in Sir Felix Semon' paper. She was allowed to use her voice fairly freely. She left again on February 13th, 1907, the larynx remaining absolutely quiescent though the state of her langs did not materially improve and was not so satisfactory.

Mr. W. I had an opportunity of seeing this patient three weeksago He was in bed after a sharp atiack of haemoptysis. He bad not been in good health for some time and had los about a stone in weight. He complained of some laryngeal pain. but the only abnormality discoverable in the larynx was a moderate degree of general congestion.

GrovP II.

Mrs. N., aged 31. She arrived at Linford on March 4th 1903. She had a small haemoptr sis at the age of 18 , hut otberwise remained well until Decomber, 1899, after the birth of a child. Since then she bad snffered with coogh, expect oration child. Since then she bad snffred with coogh, expectoration, atgact of left-sided dry pleurlsy, which kept her in bed fcr attack of left-sided dry pleurlsy, which kept her in bed cr three weeks. On her arrival she was found to have ; xtensice
tnberculous disease of both the left npper and lower lobes a'd slighter disease of the right 8 p $x$ and apex of the right lower loje. There was a history of hoarseness, dysphag a, dis- 
comfort and pain in the larynx dating back for some months The larynx showed considerable swelling of both arytenolds and anytenoid fold, which was further the seat of ulceration partially granulating and chronic in appearance, and extendIng ontwards on to the left arytenoid. The left cord w8s fleshy-looking in its posterior half, and moved badly. Strict silence ' was ordered and rigidly persevered in. On account of the great irritability of the larynx and the May 12th, 1903, there was still some arytenoid swelling, the left cord moved better, but was still flesby, and the ulceration appeared almost to have healed. There was now no dysphagia of laryngeal pain. On June 20th, the swelling of the aryteof laryngeal pain. On June 20th, the swelling of the arytevory slight, but there was a small ulcer'below the centre of the atytenoid fold of comparatively recent origin. On August 14th the larjnx appeared practically normal except for the small aperficial ulcers above mentioned, which had, however, not ipcreased in size. The patient returned home on Augast 21st, having gained $27 \mathrm{lb}$. in weight and very greatly improved in overy respect. After she left the ulcer was for a time treated with lactic acid, bat silence was not persisted in. She returned to Linford for a few weeks on July 10th, 1904. She had lost $8 \mathrm{lb}$. in weight, and was not in such good general health as she had been when she left the previous year, and had recently again been when she left the previous year, and had recently again had a little haemoptysis and some lelt-sided dry pleurisy. The
laryn $x$ appeared normal, except for a small ulcer below the centre of the left arytenoid fold. This received several applications of 50 per cent. lactic acid, and sllence was again perserered in. She left again on $\Delta$ ugust 4th, 1904. when the ulcer was beginning to granulate. This patient died at home on April 27th. 1905, but, so far ss could be ascertained, without anv recrudescence of laryngesl symptoms.

Mrs. M. aged 33, arrived at Linford on June 24th, 1903. Her lúng disesae dated from an attack of left pleural effusion in Augast, 1901, occurring a month after the birth of a child, but she got much worse after a second attack of left-sided dry pleurisy in July, 1902, which was immeand expectoration. The laryngeal symptoms dated from February, 1903. She had on arrival disease scattered through both left upper and lower lobes. Tubercle bacilli were numerous in the sputum. There was a fairly large ulcer affecting the arytenoid fold and spreading on to the base of the left cord and congestion of both cords, with laryngeal pain, dysphsigis and congestion cf both cords, with laryngeal pain, dysphagia, fairly rigorously carried out. Lactic acid was applied about once a week; first 50 per cent. and then pure. On July 27th the laryngeal pain and dysphagia were less, and the voice was clearer. On August 20th there was some patchy reddening of both cords, but only a trace of the arytenoid ulcer was left. The lactic acid treatment was discontinued. This patient left on September 19th, when the only abnormality to be seen in the larynx was some epithelial thickening over the site of the previous ulcer. She gained $15 \mathrm{lb}$. in welght, was in good general health, had lost all dyspnoes, and her cough and general health, had lost all dyspnoes, and her cough and expectoration were much less. Tabercle bacilli were, howyear ago, when she reported herself in fair general health, and free from any laryngeal symptom.

Mr. E, aged 42, arrived at Linford July 7th, 1906. He gave a short history dating only a month back. The onset was sadden and fairly severe, with bad night-sweats, cough, mucopuralent expectoration, and great languor. At the same time his voice became increasingly husky. Tubercle bacilli were present in moderate numbers. There was scattered infiltrapresent in moderste numbers. There was scattered infiltra-
tion of the right apper lobe to the third rib, and of the apex tion of the right apper lobe to the third rib, and of the apex
df the lower lobe. The temperature was at first raised in the df the lower lobe. The temperature was at first raised in the
evening to $100: 6^{\circ}$ or $101^{\circ} \mathrm{F}$. The left vocal cord was irregularly s'wollen and reddened and granular in its posterior balf; otherwise the larynx was normal. He was kept in bed and strict silence advised and practised. In two months' time the temperature slowly fell to normal, and remained so. By October 26th, 1906, the swelling of the left cord had subsided, but it still showed a pink granular appearance in its posterior half. At the end of November, 1906, the larynx was normal except for a slight'streaky reddening of both cords. Some use of the voice was now allowed. He left at the beginning of Jenuary, 1907. The larynx then appeared normal, and bis voice was natural. He gained a'stone in weight, but still had a little sputum containing tubercle bacill in small numbers.

Miss G., aged 29, arrived at Linford on December 24th, 1906. she bad suffered from recurrent hosrseness, loss of voice, with pain often shcoting upwards towards both ears, and laryngeal cough for five years, dating from an attack of influenza. For eighteen months she had lost weight. There was very early infiltration of the left apex. She bad no sputum. A considerable variety of applications had been made to the larynx without mach benefit. The pharynx was much reddened. The karynx showed marked general congestion and slight swelling of the ventricular bands. No local treatment was applied to the larynx. Strict silence was advised, and most rigidly carried out. To facilitate silence, and on account of the low state of general nutrition, she was kept entirely in bed, although her temperature was normal. She only remained at the sanbatorium for a month. At the end of her stay both laryngeal and pheryngeal congestion had decitedly decreased; and the larynx felt much more comfortable. This observation was corroborated independently on her return to town.

Miss W., aged 37, came to Linford on January 10th, 1907. She has a very bad family history of phthisis. Bhe has suffered from winter cough for years. During Angust, 19C6, she began to fail in health, lost weight, and developed a cough with expectoration. Six weeks before her arrival sbe had an attack of influenzs with high fever for two or three days, and exacerbation of all her symptoms since. She has had hoarse ness and occasional loss of voice since Christmas, 1906. On her arrival tubercle bacilli were fairly numerous in the ser arrival tubercle bacilli were fairly numerous in the upper lobe to about the third rib and of 'the apex of the left lower lobe. There were doubtful signs at the right apex. 8he complained of discomfort but no pain in the larynx and was very hosrse. The larynx showed morked general congestion, including the cords, and slight swelling over the arytenoid fold. Silence was enforced and fairly etrictly adhered to. No local treatment was adopted bejond a spray of glycothymoline. She has been kept in bed a good deal, becsuse, for two or three weeks at a time, her temperature because, for two or three weeks at a time, her temperature
in the evenings goes up to $100^{\circ}$ or $100.6^{\circ} \mathrm{F}$. On February 14th the larynx still showed marked general congestion, but the swelling of the arytenoid fold had subsided. On March 5 th, again appeared somewhat swollen. At the end of March the laryngeal congestion had further decreased and she complained of no discomfort now. On May 30th, 1907, the larynx was only very slightly reddened. There was no swelling of the arytenoid fold. The voice was more normal, but at the base of the left cord there was a small red elevation. She is still undergoing treatment and her lung condition has remained stationary in spite of the laryngeal improvement.

Mr. D. C., aged 30, arrived at Linford on February 23rd 1907. He developed a cough at the end of 1900. In March, 1902, he was found to have slight pulmonary tuberculosis and was treated for three months at the Nordrach in Wales Sanatorium, Llanbedr. He left there free from sy mptoms and in $\in$ xcellent general health. In September, 1902, he complained of "sore throat and hoarseness, and was found by Sir Felix Semon the vocal cords, and erosion of the left vocal process the vocal cords, and erosion of the left vocal process. He was
sent to Bournemouth. Off and on slight ulceration of the sent to Bournemouth. Off and on slight ulceration of the July, 1903, before going to South Africa, his larynx still showed congestion of the vocal cords and come swelling of the ventricular bands. He worked hard as a mine-owner, spending many hours daily underground in a hot, moist, and dusty atmosphere at Salisbury (Rhodesia). He had dysentery in November, 1906, which pulled him down a good deal, and led to a return of cough and expectoration. He also had malaria. In January, 1907, tubercle bacilli were found to be numerous in the sputum. He then returned to England for a long holisputum. He then returned to England for a long holi-
day. He was seen by Sir Fellx Semon at the beginday. He was seen by Sir Fellx Semon at the begin-
ning of February, 1907, who again found swelling of the ventricular bands, and congestion of the vocal cords. The patient complained of discomfort and slight pain in the larynx. He has been a heavy smoker, but has not smoked for a year. Tubercle bacilli were numerous in his sputum on arrival at the sanatorium, and he was found to have disease scattered through the left apper lobe and apper half of the upper part of the right lower lobe. He was directed to maintain absolute silence and not to smoke, and these instruction he has most rigidly carried out. In addition to the open-air treatment, he has received tuberculin in jections with observations of the opsonic index. Theonly local treatment to thelarynx hasconsisted of a menthol and carbolic spray. Thelarynge al condition has steadily improved. The swelling of the ventricular bands has subsided. The congestion of the left cold has almost disappeared and the only remaining abnormality now is patchy injection of the right cord. $\mathrm{He}$ has lost all pain and discomfort in the larynx, and his voice is nearly normal. He has further gained 17 lb. in weight, has almost lost all expectoration, and at the last examination tubercle bacilli
were only present in very small numbers; he is still undergoing treatment.

Mr. A., aged 19, arrived at Linford March 11th, 1907. He gave only six weeks' history of illness, beginning with rightsided dry plearisy which kept him in bed three weeks. At the same time a cough developed, with thick yellowish-green expectoration. He also. suffered with loss of appetite, wasting, husky, and he complained of pain localized in the posterior part of the larynx. On his arrival tubercle bacilli were found to be very numerous in the sputum, and his temperature ranged from $99^{\circ} \mathrm{F}$. in the morning to about $102^{\circ} \mathrm{F}$. at night, and there was evidence of active disease in both upper lobes. The sputum was profuse and parulent. His voice was weak; larynx was intensely reddened, and the cords espeoislly were deep red and velvety in appearance. He was kept entirely in bed and cautioned to maintain silence, which was pretty well ins ured by isolation in his own. room and on the sanatorium terrace. The larynx was sprayed four or five times a day with a menthol and carbolio solution. His temperature came down slowly and irregularly, and was normal by April 5th. The
spatum decreased in amount, and is now very little. He has 
gained $10 \mathrm{lb}$. in weight. $\mathrm{He}$ is up all day and beginning to take exercise. On April 5th there was less laryngeal pain. cords were puler and less velvety. By May 15th the largnx appeared practically normal ; the voice was normal, and there was no abnormal laryngeal sensation whatever. He has since that date been allowed to talk a good deal. $\mathrm{He}$ is still undergoing treatment.

\section{MEMORANDA; MEDICAL, SURGICAL, OBSTETRICAL.}

MYXOEDEMA AND EXOPHTHALMIC GOITRE. ALtнodgh it has been recognized for some years that myxoedema may intervene in the later stages of exophthalmic goître, the cases are sufficiently unusual to be worth recording. The patient reported below first sought advice three years ago, and gave the following history:

History. - A. B., a woman aged 52 married, had always enjoyed good health until the strain of eleven pregnancies in quick succession undermined her constitution. At 31 years of age she sought advice, as she was in a very weak and nervous condition. She had for some time noticed that her throat was swollen, that her eyes were becoming large and prominent, and that her hands trembled so that she could not execute fine movements, such as threading a needle. She got out of breath on the slightest exertion, and suffered with very distressing palpitation. She was treated with medicine and electricity palpitation. She was treated with medicine and electricity
from time to time for years, at the end of which her condition improved. Three years ago she again sought advice : for some time she had been getting too stout was unable to walk far, and dyspnoes was brought on by trivial exertion.

State on Examination. - She presented the typical appearance of a case of myxoedema, there was a large increase in th bodily bulk, the weight being 12 st. The skin was dry and coarse, and there was considerable swelling of the subcutaneous tissues throughout the body, which did not pit on pressure. The sapraclavicular pads of fat were well m pressure. The sapraclavicular pads of fat were well both malar bones, and there had been a considerable loss of hair, that remaining being dry and coarse. The gait was slow and clumsy, and the patient seemed incapable of mental exertion. There was no sign of a tumour in the thyroid region. and no exophthalmos. The temperature was subnormal, being $97.2^{\circ}$. The cardiac dullness was slightly increased to the left, and a systolic murmur was audible at the apex. The pulse was regular, 62 to the minute; moderate volume and tension; the vessel wall was thickened.

Treatment. - The patient was placed on thyroid extract and improved in a wonderfal way, losing $9 \mathrm{lb}$. in weight during the first fortnight. If the treatment is discontinued she rapidly begins to relapse to her former state.

Rrmarks. - In the Transactions of the Clinical Society, 1900, Pasteur published a case in which some of the symptoms of Graves's disease persisted, while those of myxoedema supervened. In this case no benefit resulted from thy roid extract. Faure also recorded a case of this kind (Presse Méd., Paris, 1899), but in looking up the recent literature I can find no case where the two diseases occurring in the same individual were so separate and distinct.

Chigwell.

Srmonds Gooding, M.A., M.B.Cantab.

PHLEBOLITHS AND THE ROENTGEN RAYS. REOHNTLY two very interesting cases came under my notice which appear to be worth recording.

1. A male, aged 32, complained of dull aching pain deep down in the pelvis on the right side. It had been present for the past two years, and was more or less of a constant character, very little affected by rest or exercise. The urine contained a slight excess of phosphates, otherwise it was normal. Eighteen months previously his appendix had been removed by an eminent London surgeon, who afterwards told the patient that there was very little to account for his symptoms so far as this structure was concerned. Very slight benefit resulted from the operation. It was thought by several medical men who examined him here that he might possibly have a ureteral calculus on the right side. He was accordingly sent to me, and two excellent Roentgenograms presented the same appearance-what seemed to be two small ureteric calculi on the right side, one near the termination of the ureter and the other an inch higher up; they were the size of small shot. Feeling confident that I had discovered two ureteric calculi I made my diagnosis accordingly. The patient was then sent into a private hospital, and a suprapubic operation was performed. The surgeon palpated the right ureter but felt nothing. The ureter was then catheterized, with negative result. He then passed one finger into the rectum, and with the other hand in the bladder could distinctly feel two shotty bodies as indicated by the Roentgenograms. Their position was just a little outside the line of the ureter and on a deeper plane. Nothing further was done. Afterwards the patient was carefully questioned as to whether he had ever been accidentally shot, and he could positively answer this question in the negative. Convalescence was uneventful, and I have not seen the patient since.

2. A man, aged 38 , had been complaining of pains in the right testicle and the region of the ureter on that side on and off for ten years. The pain was never severe. The urine was normal. A Roentgenogram revealed a small, shot-like body on the right side on a level with the lower end of the ureter, but an inch outside. On this occasion my diagnosis was a phlebolith. No operation was performed. I am quite confident, too, that on the first occasion the shadows were those of phleboliths.

Quite recently I mentioned these cases to Professor Watson of Adelaide, and he quite agrees with my interpretation. He mentions that it is not at all uncommon to find phleboliths in these positions during the course of post-mortem examinations, and expressed the opinion that they occur more frequently during life than is generally supposed.

Referring to phleboliths, Qaain in his Dictionary of Medicine says :

Phleboliths, or venous calculi, tend to form in veins in which circulation is slow, as in the veins of the prostate and bladder, and in varicose veins anywhere. They commence, no doubt, as precipitated fibrin, which becomes infiltrated with the less as precipitated fibrin, which becomes infiltrated with the less
soluble salts of the blood, chiefly phosphate of aslcium, and in soluble salts of the blood, chiefly phosphate of aslcium, and in
less quantity sulphate of calcium and sulphate of potassium.

In concluaion, I would only say that the Roentgenogram must be very carefully taken, so that differentiation in the tissues may be clearly evident.

L. Hmrscher Harris. M.B.. Ch.M. (Sydney, N.9.W.), Honorary Assistant Burgeon and Senior Honorary Bkiagrapher, Sydney Hospital.

\section{PLUGGING THE POSTERIOR NARES.}

THe ordinary method is both rough and horribly uncomfortable to the patient. The method which I have devised is as follows: Pass the usual double thread (preferably of silk) through either nostril, using for the purpose an eyed probe, if the surgeon possesses one of sufficient length. Such an implement is a nearer approach to a Eustachian catheter in calibre than a Bellocq's sound or any urethral catheter; as all aurists soon learn, even a small Eustachian catheter sometimes fails to pass. Repeat the process through the other nostril with a fresh thread. The loose ends hanging from the mouth are now tied to each other and round a plug of gauze or of lint, and are cut short.

By pulling on the ends hanging from the nostrils, and aided by a finger in the mouth, the plug is dragged up behind the soft palate, and more or less to one posterior nostril as may be necessary. Next (if required) plug one or both anterior nares, thread the silk ends through a piece of rubber tubing, and tie either in front of the nose or across the cheeks and behind the neck. Keep these ends long, so as to control the plug when, next day, it is pushed back into the mouth for removal.

By this plan the discomfort to the patient is reduced to a minimum.

Iondon, E.C.

A. Ogier Ward. M.D.

UNDER the will of the late Mr. George Francis Moth, of Brixton, who died on May 7th, the National Hospital for Paralysis, and the Royal London Ophthalmic Hospital each receive a sum of $£ 100$.

The Protozoal Theory of Cancer and Syphilis.Professor Max Schüller of Berlin is still a vigorous upholder of the theory that both malignant disease and syphilis are caused by parasites which he describes as protoz Ja. He has reiterated his views in articles which have recently appeared in German scientific journals (Berl. Klin. Woch., No. 9, 1907, and Centra:bl f. Bakt., Abt. I , Orig., Bd. 43, 1907), and supports his statements by reproductions from photographs of the appearances in carcinoma, sarcoma, and syphilis which he regards as protozoan parasites. 